\title{
Rethinking Corporate Security in the Post 9/11 Era by Dennis Dalton
}

\author{
Boston, MA: Butterworth Heinemann (2003) ISBN 0750676140
}

(331 pages, \$39.95/£26.99)

\section{Reviewed by Robert Stokes}

Clearly, the events of 9/11 left an indelible mark on the psyche of the United thes and the world. The fact that security and emegency response failures contributed to the calamity has been noted in innumerable outlets. The unfortunate events of that fateful day have also led to a new paradigm in security management. This paradigm has arguably elevated the status (if not pay) of security professionals; created a greater market cry for security services and products; and in some cases, expanded levels of cooperation and information exchange between public and private purveyors of security services. Moreover, the catastrophic events of 9/1 1 have reawakened the security community to the threats of terrorism.

In this book Dalton posits a new paradigm for corporate of ficers, a paradigm that elevates the threat of terror to corporate assets above pre-9/1 1 preoccupations with workplace violence, computer crime and identity theft. So, what has this new paradigm wrought in terms of strategies and modalities for security provision in the private sector?

Dalton offers the following questions to organize his thesis:

- What is security's value-added contribution in a world of tangible and intangible assets?

- What are the challenges in protecting people-employees and assigned strategic partners?

- What role does security have in the fight against the loss of competitive intelligence and intellectual property?

- How does one move rapidly but efectively from a management style of dictating to one of collaborating?

Dalton's introduction is a treatise on professional survival.A lament often heard among security professionals is their tenuous place in the corporate or ganizational landscape. Dalton reasserts this concern, while offering a prescription for earning what this reviewer would term the 'three Rs' for effective managers: respect, resources and responsibility. Clearly, security professionals are not on an equal footing in terms of positioning their operations at the corporate table. This difficulty is fundamentally rooted in a corporate structure oganized around an accounting mentality of costs and profits. Is security a cost? If so, it should be cut. Or is it a profit center, with losses avoided considered profits gained? Further, what is the role of security if many of its core areas of control and responsibility have been atomized and parsed out to other functionaries in the corporate organization? Much of Dalton's book addresses these questions.

The body of the book is or ganized into three parts, containing a total of nine chapters. Part I describes a security environment in flux. The main point of this section rests in its assertion that the events of $9 / 11$ have reduced the level of analytic importance given to the strategic planning 
role of security executives. In other words, the limited movement towards proactive planning for total asset protection prior to $9 / 11$ has given way to a more reactive chage for security operatives to merely protect facilities from attack.

Part II provides justification for a return to a strategic approach towards the goals of successful security management, with the security manager taking on a more integrative role in a systematic approach to asset protection. Here, the security operative has a say over seemingly disparate operations that are strategically linked or form a line of critical exposure. Moreover metrics are offered to gauge risk and to instruct resource allocation decisions. Part III involves Dalton' s recipe for success in security planning. Here, he of fers guidelines informed by his years of experience in law enforcement and corporate security.

Overall, Dalton's work is a unique effort to get away from the cookie-cutter solutions to security problems that often vex standard texts in the field. He does not delve into the standard minutiae often found in security texts (thankfully, no chapters on locks and alarms); instead, he of fers a strategic vision for security as a product/service, as well as an internal political strategy for security professionals to better position themselves as a company asset.

While these distinguishing characteristics made the book comparatively enjoyable to read, from an empirical point of view it is weakened by too many personal anecdotes, self-congratulatory insights and an informal writing style for this reviewer 's taste. In other words, the book reads more like a highly personalized treatise on the politics of security rather than an evidence-based assessment of security effectiveness. This proves to be both the book's primary strength as well as a weakness, especially in light of Daltons desire to see more and better research in the field of security. Ironically, the author notes in his introduction that both academics and the private sector have been remiss in failing to test the suppositions held by security operatives regarding the efficacy of their strategies.A short survey of his bibliography however, finds a citation list devoid of empirical assessments and long on corporate 'guru'-style contributions. Clearly, within the pages of this journal as well as of others dealing in security , criminology, risk assessment and business operations management, there are numerous studies of security operational ffectiveness.

In conclusion, if you are looking for an insider's view of the history, culture, politics and current state of corporate security, this is the book for you. Dalton clearly has a wealth of experience and insight to inform even the most stagnant corporate security program. His focus on refiffming the strategic role of the security professional is a commendable one. Dalton's critique of 'window dressing' threat assessment systems, when couched in a broader discussion of the overall lack of analytic rigor in the public and private sectors of the profession, is instructive and, pardon the pun, alarming. Dalton's main contribution with this book, howeveris in its clarion call to security professionals (and their corporate bosses) to maintain a 'big-picture', systematic outlook on the role of security in asset protection and management. In light of the raised stakes imposed by 911 here's hoping this call does not go unheeded.

Robert Stokes

School of Urban and Public Affairs

University of Texas at Arlington 